\title{
Electrophilic Aromatic Trifluoromethylthiolation with the Second Generation of Trifluoromethanesulfenamide
}

\author{
Sébastien Alazet ${ }^{a, b}$ \\ Thierry Billard*a,b \\ a Institute of Chemistry and Biochemistry (ICBMS, UMR CNRS \\ 5246), Université de Lyon, Université Lyon 1, CNRS, 43 Bd du \\ 11 novembre 1918, 69622 Lyon, France \\ Thierry.billard@univ-lyon1.fr \\ b CERMEP, In Vivo Imaging, Groupement Hospitalier Est, 59 Bd \\ Pinel, 69003 Lyon, France
}

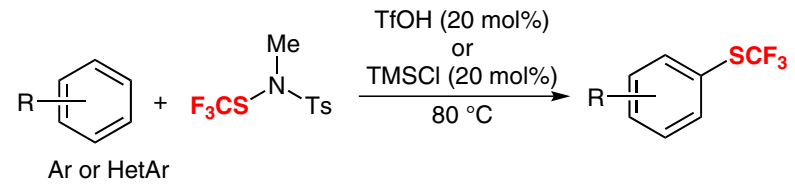

Table 1 Trifluoromethylthiolation of $\mathbf{2 a}$ with $\mathbf{1 a}$

Accepted after revision: 03.11.2014

Published online: 28.11 .2014

DOI: 10.1055/s-0034-1379501; Art ID: st-2014-b0820-c

Abstract Direct trifluoromethylthiolation of various aromatic and heteroaromatic compounds, variously substituted, can be performed with the second generation of trifluoromethanesulfenamide via a 'FriedelCrafts-like reaction'. This reaction requires mild conditions with a catalytic amount of protic or Lewis acid. Good results have been obtained, even with aromatic compounds bearing deactivating substituents.

Key words trifluoromethylthiolation, fluorine, arenes, heterocycles, trifluoromethanesulfenamide

Because of the intrinsic properties of the fluorine atom, fluorinated compounds have known these last years an increasing interest in a large panel of applications, from materials to life sciences. ${ }^{1}$ In this last field, the introduction of fluorinated group generally contributes to better physicochemical properties. ${ }^{2}$ In particular, the $\mathrm{CF}_{3} \mathrm{~S}$ group, because of its high lipophilicity (Hansch parameter $\pi_{R}=1.44$ ), ${ }^{3}$ can favor the transmembrane permeation and, consequently, increase the biodisponibility of molecules. ${ }^{4}$

A lot of methods have been described in literature to synthesize compounds bearing this specific group. ${ }^{5}$ However, these methods are essentially indirect methods which could require aggressive reagents. The most efficient, and elegant, way to easily access the trifluoromethylthiolated molecules is the direct introduction of the $\mathrm{CF}_{3} \mathrm{~S}$ moiety. Recently, some elegant solutions have emerged to enable one to propose an efficient toolbox to organic chemists. Thus, various reagents for nucleophilic or electrophilic reactions are now available for a large panel of reactions. ${ }^{5 a, b, 6}$ Nevertheless, only a few classic electrophilic aromatic substitutions have been described.

If we exclude the $\mathrm{CF}_{3} \mathrm{SCl}$ chemistry, because of the high toxicity of this gaseous compound, ${ }^{7}$ the first generation of trifluoromethanesulfenamide has been the first reagent able to perform 'Friedel-Crafts-like reaction'. However, these reactions were limited to electron-rich aromatic compounds such as indoles. Later, a trifluoromethanesulfonyl hypervalent iodonium ylide reagent was also successfully

\begin{tabular}{llllll} 
& & & & & 3 \\
\hline
\end{tabular}

a Crude yield was determined by ${ }^{19} \mathrm{~F}$ NMR using $\mathrm{PhOCF}_{3}$ as an internal standard.

employed to trifluoromethylthiolate indoles. ${ }^{9}$ Shen et al. have also published lately the trifluoromethylthiolation of indoles in mild conditions with their trifluoromethanesulfenate reagent. ${ }^{10}$ Very recently, $N$-trifluoromethylthiosaccharin has been developed and a larger panel of aromatics could be trifluoromethylthiolated with this new reagent. ${ }^{11}$ Nevertheless, to this day, it appears that the electrophilic aromatic trifluoromethylthiolation is still in progress and further methods are expected to extend the investigations. 
<smiles>COc1ccc(S(F)(F)F)c(OC)c1</smiles>

3a<smiles>Oc1ccc(S(F)(F)(F)(F)F)c(O)c1</smiles>
$86 \%(98 \%)^{\mathrm{a}}$<smiles>COc1ccc(O)c(C(F)(F)F)c1</smiles>
$45 \%(60 \%)^{a}$<smiles>Oc1ccc(S(F)(F)F)c(Br)c1</smiles>

3i

$(34 \%)^{\mathrm{a}}$ $55 \%(86 \%)^{b}$<smiles>Oc1ccc(Br)cc1C(F)(F)F</smiles>

3j

$(14 \%)^{\mathrm{a}}$ $50 \%(65 \%)^{b}$
$\mathrm{TfOH}$

2 or 1 equiv) $\rightarrow \mathrm{Ar}-\mathrm{SCF}_{3}$

3<smiles>COc1ccc(S(F)(F)(F)(F)F)cc1</smiles>

$3 c$

$58 \%(66 \%)^{\mathrm{a}} \quad 82 \%(90 \%)^{\mathrm{a}}$

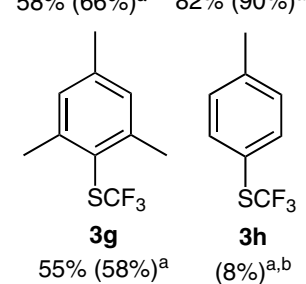

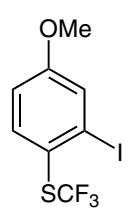

3k

$(18 \%)^{\mathrm{a}}$ $81 \%(86 \%)^{b}$<smiles>Oc1ccc([Se]C(F)(F)F)cc1</smiles>

$3 d$

$$
\mathrm{SCF}_{52 \%(56 \%)^{\mathrm{b}}}^{\mathrm{3m}}
$$

Scheme 1 Electrophilic aromatic trifluoromethylthiolation with 1a, catalyzed by $\mathrm{TfOH}$. ${ }^{\text {a }}$ The reaction was carried out with 0.2 equiv of $\mathrm{TfOH} .{ }^{\mathrm{b}}$ The reaction was carried out with 1 equiv of $\mathrm{TfOH}$. Isolated yields (in parentheses, crude yields determined by ${ }^{19} \mathrm{~F}$ NMR titration with $\mathrm{PhOCF}_{3}$ as internal standard).

Recently, we have developed a second generation of trifluoromethanesulfenamide (1a) that is more reactive and which has been successfully used to carry out reactions that were impossible to realize with the first-generation reagent. ${ }^{12}$ In this context, to continue the exploration of the reactivity of this new reagent and, also, to propose new tools for electrophilic aromatic trifluorometylthiolation, we decided to study 'Friedel-Crafts-like reactions' with $\mathbf{1 a}$.

To determine the optimal conditions, $m$-dimethoxybenzene has been chosen as the model substrate (Table 1).
If Lewis acids were not efficient to favor this reaction in dichloromethane (Table 1, entries 1-3), Brönsted acid, such as triflic acid, was very efficient to catalyze this reaction (Table 1, entries 4-6). With one equivalent of TfOH, no temperature effect on the yield was observed (Table 1, entries 4-6). Given the mechanism of the $\mathrm{S}_{\mathrm{E}} \mathrm{Ar}$, the required proton amount should be catalytic. Indeed, only 0.2 equivalent of TfOH appeared to be sufficient. Nevertheless, in this case, heating to $80^{\circ} \mathrm{C}$ was required to favor the kinetics (Table 1 , entries 7-9). A solvent effect was observed for the TMSCl catalysis since good results were obtained in acetonitrile, with stoichiometric or catalytic amount, (Table 1, entries 14 and 15) whereas nothing happened with one equivalent in $\mathrm{CH}_{2} \mathrm{Cl}_{2}$. In term of kinetics, the optimal reaction time was determined to be around 18 hours (Table 1, entries 9-13).

With the optimal conditions in hand (Table 1, entry 9), various aromatic compounds were engaged in this reaction (Scheme 1). ${ }^{13-15}$

The reaction gave, in general, good yields with various aromatic compounds. The trifluoromethylation of toluene remained unsatisfactory, which is certainly because it is not sufficiently electron-rich. On the contrary, mesitylene was trifluoromethylated with satisfactory yield $(\mathbf{3 g})$. When the trifluoromethylthiolation was difficult, the use of one equivalent of $\mathrm{TfOH}$ was, generally, beneficial and good yields could be then obtained, even in the case of nitro compounds (31).

In the case of protic acid sensitive compounds, such as nitrogenated molecules, catalysis with TMSCl was considered (Scheme 2). Good yields were then obtained. Again, the use of one equivalent of TMSCl was required to increase the obtained yields.

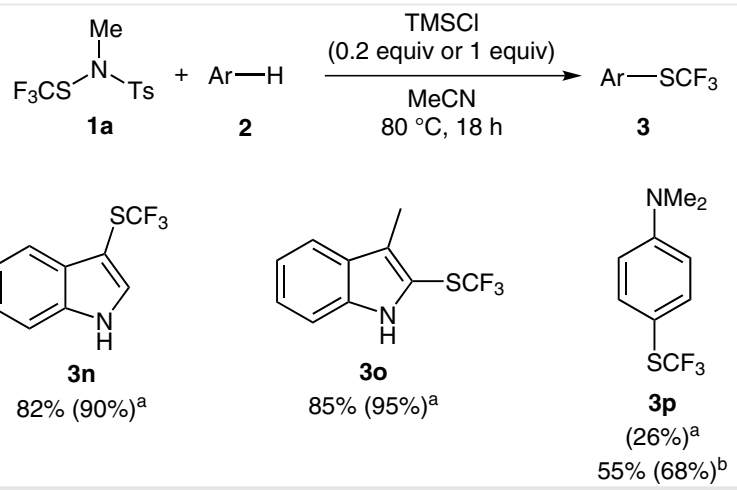

Scheme 2 Electrophilic aromatic trifluoromethylthiolation with 1a, catalyzed by $\mathrm{TMSCl}$. ${ }^{a}$ The reaction was carried out with 0.2 equiv of TMSCl. ${ }^{\text {b }}$ The reaction was carried out with 1 equiv of $\mathrm{TMSCl}$. Isolated yields (in parentheses, crude yields determined by ${ }^{19} \mathrm{~F}$ NMR titration with $\mathrm{PhOCF}_{3}$ as internal standard). 
Since the superior homologue of 1a is also easily available, a few examples of pentafluoroethylthiolation were also performed (Scheme 3). Good yields were observed also for this reaction.

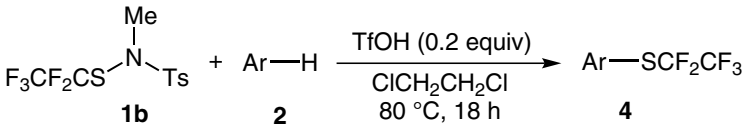

$$
\begin{aligned}
& \text { (c) } \\
& 4 a \quad 4 d \\
& 68 \%(76 \%) \quad 56 \%(78 \%)
\end{aligned}
$$

Scheme 3 Electrophilic aromatic pentafluoroethylthiolation with 1a, catalyzed by $\mathrm{TfOH}$. Isolated yields (in parentheses, crude yields determined by ${ }^{19} \mathrm{~F}$ NMR titration with $\mathrm{PhOCF}_{3}$ as internal standard).

To conclude, the second generation of trifluoromethanesulfenamide, which we have recently developed, confirms its higher reactivity, compared to its first-generation counterpart. With this new reagent, electrophilic aromatic trifluoromethylthiolations can be performed in mild conditions (catalytic amount of acid) with various aromatic compounds. For the first time, aromatics bearing alkyl or nitro compounds have been successfully trifluoromethylthiolated. Furthermore, the extension of these reactions to pentafluoroethylthiolation has been initiated. Therefore, this family of reagent confirms its effectiveness and its place into the toolbox of trifluoromethylthiolating reagents.

\section{Acknowledgment}

The CNRS and the French Ministry of Research are thanked for their financial supports. The French Fluorine Network is also thanked for its support.

\section{Supporting Information}

Supporting information for this article is available online at http://dx.doi.org/10.1055/s-0034-1379501.

\section{References and Notes}

(1) (a) Kirsch, P. Modern Fluoroorganic Chemistry: Synthesis, Reactivity, Applications; Wiley-VCH: Weinheim, 2013. (b) Hagmann, W. K. J. Med. Chem. 2008, 51, 4359. (c) Purser, S.; Moore, P. R.; Swallow, S.; Gouverneur, V. Chem. Soc. Rev. 2008, 37, 320. (d) Hird, M. Chem. Soc. Rev. 2007, 36, 2070. (e) Muller, K.; Faeh, C.; Diederich, F. Science 2007, 317, 1881. (f) Jeschke, P. ChemBioChem 2004, 5, 570. (g) Smart, B. E. J. Fluorine Chem. 2001, 109, 3. (h) Hiyama, T. Organofluorine Compounds: Chemistry and Applications; Springer: Berlin/Heidelberg, 2000. (i) Becker, A. Inventory of Industrial Fluorobiochemicals; Eyrolles: Paris, 1996.

(2) (a) In Fluorine in Medicinal Chemistry and Chemical Biology; Ojima, I., Ed.; Wiley: Chichester, 2009. (b) Begue, J.-P.; BonnetDelpon, D. Bioorganic and Medicinal Chemistry of Fluorine; John Wiley \& Sons, Inc: Hoboken, 2008, 365.

(3) Hansch, C.; Leo, A.; Taft, R. W. Chem. Rev. 1991, 91, 165.

(4) (a) Avdeef, A. Absorption and Drug Development: Solubility, Permeability, and Charge State; Wiley: Hoboken, 2012. (b) Smith, D. A.; Allerton, C.; Kubinyi, H.; Walker, H.; Walker, D. K.; Mannhold, R.; Folkers, G. Pharmacokinetics and Metabolism in Drug Design; Wiley-VCH: Weinheim, 2012. (c) Clark, D. E. Drug Discovery Today 2003, 8, 927. (d) Norinder, U.; Haeberlein, M. Adv. Drug Del. Rev. 2002, 54, 291. (e) Kelder, J.; Grootenhuis, P. D. J.; Bayada, D. M.; Delbressine, L. P. C.; Ploemen, J.-P. Pharm. Res. 1999, 16, 1514

(5) (a) Toulgoat, F.; Alazet, S.; Billard, T. Eur. J. Org. Chem. 2014, 2415. (b) Xu, X.-H.; Matsuzaki, K.; Shibata, N. Chem. Rev. 2014, in press; doi: 10.1021/cr500193b. (c) Boiko, V. N. Beilstein J. Org. Chem. 2010, 6, 880. (d) Leroux, F.; Jeschke, P.; Schlosser, M. Chem. Rev. 2005, 105, 827.

(6) (a) Landelle, G.; Panossian, A.; Pazenok, S.; Vors, J.-P.; Leroux, F. R. Beilstein J. Org. Chem. 2013, 9, 2476. (b) Tlili, A.; Billard, T. Angew. Chem. Int. Ed. 2013, 52, 6818.

(7) Stump, E. C. Chem. Eng. News 1967, 45, 51, 44.

(8) Ferry, A.; Billard, T.; Bacqué, E.; Langlois, B. R. J. Fluorine Chem. 2012, 134, 160 .

(9) Yang, Y.-D.; Azuma, A.; Tokunaga, E.; Yamasaki, M.; Shiro, M.; Shibata, N. J. Am. Chem. Soc. 2013, 135, 8782.

(10) Ma, B.; Shao, X.; Shen, Q. J. Fluorine Chem. 2014, doi: 10.1016/j.jfluchem.2014.09.011.

(11) Xu, C.; Ma, B.; Shen, Q. Angew. Chem. Int. Ed. 2014, 53, 9316.

(12) Alazet, S.; Zimmer, L.; Billard, T. Chem. Eur. J. 2014, 20, 8589.

(13) Typical Procedure: A $10 \mathrm{~mL}$ sealed tube equipped with a magnetic stirrer was charged with the arene $(0.50 \mathrm{mmol}, 1.0$ equiv $)$ and $\mathrm{TsNMeSCF}_{3}$ (1a) or $\mathrm{TsNMeSCF}_{2} \mathrm{CF}_{3}$ (1); 1.2 equiv) in anhyd DCE. The reaction was stirred at r.t. for $1 \mathrm{~min}$ and triflic acid was added slowly ( 0.2 equiv) and the reaction was stirred at $80{ }^{\circ} \mathrm{C}$ for $18 \mathrm{~h}$. The progress of the reaction was checked by ${ }^{19} \mathrm{~F}$ NMR with $\mathrm{PhOCF}_{3}$ as internal standard. After completion, the reaction was warmed to r.t. and the solvent was removed under vacuum and the residue was purified by flash chromatography to give the desired product.

(14) 4-[(Trifluoromethyl)sulfanyl]benzene-1,3-diol (3b): brown solid; mp <50 ${ }^{\circ} \mathrm{C} .{ }^{1} \mathrm{H}$ NMR: $\delta=7.41\left(\mathrm{~d},{ }^{3} \mathrm{~J}_{\mathrm{H}, \mathrm{H}}=8.6 \mathrm{~Hz}, 1 \mathrm{H}\right), 6.56$ $\left(\mathrm{d},{ }^{3} J_{\mathrm{H}, \mathrm{H}}=2.7 \mathrm{~Hz}, 1 \mathrm{H}\right), 6.85\left(\mathrm{dd},{ }^{3} J_{\mathrm{H}, \mathrm{H}}=8.6,2.7 \mathrm{~Hz}, 1 \mathrm{H}\right), 4.50-$ 6.10 (br, $2 \mathrm{H}$ ). ${ }^{13} \mathrm{C}$ NMR: $\delta=161.1,159.5,139.6,128.8\left(\mathrm{q},{ }^{1} J_{\mathrm{C}, \mathrm{F}}=\right.$ $315 \mathrm{~Hz}), 109.9,103.0,99.62\left(\mathrm{q},{ }^{3} J_{\mathrm{C}, \mathrm{F}}=1.7 \mathrm{~Hz}\right) .{ }^{19} \mathrm{~F}$ NMR: $\delta=$ -44.52 (s, 3 F). Anal. Calcd for $\mathrm{C}_{7} \mathrm{H}_{5} \mathrm{~F}_{3} \mathrm{O}_{2} \mathrm{~S}: \mathrm{C}, 40.00 ; \mathrm{H}, 2.40$; $\mathrm{S}$, 15.26. Found: C, 40.12; H, 2.29; S, 15.47.

(15) Synthesis of 2,4-Dimethoxy-1-[(pentafluoroethyl)sulfanyl]benzene (4a): ${ }^{1} \mathrm{H}$ NMR: $\delta=7.51\left(\mathrm{~d},{ }^{3} J_{\mathrm{H}, \mathrm{H}}=8.5 \mathrm{~Hz}, 1 \mathrm{H}\right)$, 6.50-6.52 (m, $2 \mathrm{H}), 3.87(\mathrm{~s}, 3 \mathrm{H}), 3.83(\mathrm{~s}, 3 \mathrm{H}) .{ }^{13} \mathrm{C}\left\{{ }^{19} \mathrm{~F}\right\}$ NMR: $\delta=$ $164.3,162.7,141.0,120.0\left(\mathrm{CF}_{2}\right), 118.9\left(\mathrm{CF}_{3}\right), 105.7,101.7\left(\mathrm{t},{ }^{3} J_{\text {, F }}\right.$ $=2 \mathrm{~Hz}), 99.3,56.1,55.62 .{ }^{19} \mathrm{~F}$ NMR: $\delta=-82.94\left(\mathrm{t},{ }^{3} \mathrm{~F}_{\mathrm{F}, \mathrm{F}}=3.4 \mathrm{~Hz}, 3\right.$ F), $-93.06\left(\mathrm{q},{ }^{3} J_{\mathrm{F}, \mathrm{F}}=3.5 \mathrm{~Hz}, 2 \mathrm{~F}\right)$. Anal. Calcd for $\mathrm{C}_{10} \mathrm{H}_{9} \mathrm{~F}_{5} \mathrm{O}_{2} \mathrm{~S}: \mathrm{C}$, 41.67; H, 3.15; S, 11.12. Found: C, 41.79; H, 2.91; S, 11.4. 